\title{
A model of chlorophyll a destruction by Calanus spp. and implications for the estimation of ingestion rates using the gut fluorescence method
}

\author{
C. J. Stevens ${ }^{1, *}$, E. J. H. Head ${ }^{2}$ \\ 'Department of Biology, Dalhousie University, Halifax, Nova Scotia B3H 4J1, Canada \\ ${ }^{2}$ Department of Fisheries and Oceans, Bedford Institute of Oceanography, PO Box 1006, Dartmouth, Nova Scotia B2Y 4A2, Canada
}

\begin{abstract}
Chlorophyll a (chl a) destruction by groups of Calanus spp. with different long-term in situ feeding histories was compared. For copepods that had fed during both pre- and early-bloom conditions, degrees of chl a destruction were relatively constant at high ingestion rates and increased as ingestion rates decreased. Assuming that 2 pools of chlorophyll bleaching enzymes (CBEs) were involved in the destruction of chl a (one derived from the copepods and one from the ingested algae), a new model was developed to describe the kinetics of chl a destruction. In this model, the CBE activity of each pool was described using a Michaelis-Menten expression and the total CBE activity was given by the sum of the 2 expressions. Parameter estimates of $V_{\text {max }}^{c}$, the maximum activity of the copepod CBE, were higher for the early-bloom copepods than for the pre-bloom copepods, suggesting that the former had a higher destructive capacity. Estimates of $R_{\text {max }}^{p}$, the phytoplankton 'CBE activity coefficient' which is analogous to $V_{\max }$, were similar between the 2 groups of experiments. This is reasonable since most of the food fed to the copepods was healthy, actively growing diatoms. The model could also describe the kinetics of chl a destruction for Calanus spp. that had fed during late-bloom conditions. For the late-bloom data, $V_{\max }^{c}$ and $R_{\max }^{p_{\max }}$ values were higher than for the pre-and early-bloom copepods and phytoplankton. This suggests that the late-bloom copepods and the in situ phytoplankton that they ate had higher destructive capacities, perhaps because the spring-bloom was more advanced. Expressions were derived from the new model to describe the relationship between real ingestion rate $\left(I_{\mathrm{r}}\right)$ and apparent ingestion rate $\left(I_{a}\right)$, over a range of $I_{a}$ values, where the latter are values which would have been determined using gut fluorescence methodology. Correction factors $\left(I_{r} / I_{a}\right)$ varied by a factor of less than 2 (for $l_{4}$ values ranging from 0.1 to $100 \mathrm{ng} \mathrm{chl} \mathrm{a}$ ind $\mathrm{.}^{-1} \mathrm{~h}^{-1}$ ) between different groups of copepods (pre-, early- and late-bloom) and sources of algae (actjvely growing and senescent). In future it will be important to validate this model under controlled conditions (e.g. using single species of copepods and phytoplankton food) and to assess whether correction factors derived from our model are generally applicable, if results of studies using gut fluorescence methods are to be interpreted properly.
\end{abstract}

KEX WORDS: Copepod grazing Chlorophyll a destruction $\cdot$ Feeding history $\cdot$ Michaelis-Menten kinetics

\section{INTRODUCTION}

The destruction of chlorophyll a (chl a) during grazing by copepods, as distinct from its degradation into a-type phaeopigments, has been a subject of controversy in the scientific literature for more than a decade (e.g. Conover et al. 1986, Lopez et al. 1988, Pasternak

\footnotetext{
- Present address: Ocean Sciences Centre, Memorial University of Newfoundland, St. John's, Newfoundland A1C 5S7, Canada. E-mail: x79cjs@morgan.ucs.mun.ca
}

\& Drits 1988, Peterson et al. 1990). The issue is important because of the widespread use of the 'gut fluorescence method' for estimating copepod ingestion rates in situ (Mackas \& Bohrer 1976). In this method it is assumed that the conversion of chl a to a-type phaeopigments in copepods' guts is $100 \%$ eftirient. Debate has therefore centred around 2 questions: firstly, does chl a destruction occur (either sometimes or always); and, secondly, if it does, then does it affect determinations of copepod ingestion rates based on the gut fluorescence method? The increasing number of reports of 
the occurrence of chl a destruction during grazing argues strongly that the process is real, although the degree to which it occurs is evidently very variable (e.g. Conover et al. 1986, Lopez et al. 1988, Penry \& Frost 1991, Head \& Harris 1992, 1996). With respect to the second question, Head \& Harris (1996) showed that chl a destruction occurs prior to the entry of chl a into copepods' guts (presumably as soon as the cells are macerated by the copepods), confirming that estimates of ingestion rates based on the gut fluorescence method are indeed likely to be in error. Thus, it appears that the gut fluorescence method is fundamentally flawed, although in view of the considerable body of data that has been collected using this method, one might hope that a thorough understanding of the factors affecting the degree to which chl a destruction occurs would enable us to 'correct' existing and future data sets

Penry \& Frost (1991) and Head \& Harris (1992) suggested that degrees of chl a destruction may vary with the long- or short-term feeding histories of copepods and Penry \& Frost (1991) and Head \& Harris (1996) showed that degrees of chl a destruction for Calanus spp. feeding on diatoms varied inversely with ingestion rate. Head \& Harris (1996) explored the relationship between the degree of chl a destruction $(\% D)$ and ingestion rate $(I)$, by explaining the process in terms of the activity of an enzyme, or group of enzymes, which they termed chlorophyll bleaching enzymes (CBEs) whose action, they postulated, might involve oxidation and porphryin-ring cleavage (Brown et al. 1991). They found that the relationship between CBE activity (i.e. the rate of destruction of chl a) and $I$ could be expressed by a straight line which had a positive slope and a positive $y$-intercept. The fact that CBE activity increased with $I$, together with observations that chl a destruction occurs very early during feeding (Head \& Harris 1996) and literature reports that chl a can be bleached in cell-free extracts of diatoms (Owens \& Falkowski 1982) and senescent diatoms (Spooner et al. 1994), led the authors to suggest that enzymes derived from the phytoplankton themselves were contributing to chl a destruction during grazing. They suggested that the positive $y$-intercept, on the other hand, is indicative of a basal level of CBE activity associated with the copepods. In this interpretation, at low ingestion rates the copepod CBE can destroy all or most of the ingested chl $a$, while at higher ingestion rates a greater proportion of the total destruction is due to the phytoplankton CBE

Using the linear function derived from the regression of CBE activity on $I_{1}$ Head \& Harris (1996) derived a curve to describe the relationship between $\% D$ and $I$. which fitted the experimental observations reasonably well: $\% D$ increased as ingestion rates decreased and there was a threshold value of $I$ below which all ingested chl a was being destroyed. At high ingestion rates the degree of chl a destruction tended to a minimum value of ca $45 \%$. Although their model did appear to fit the experimental observations, it was criticised by Bochdansky \& Deibel (1997) on the grounds that the relationship between CBE activity and $I$ should not have been expressed using a straight line, since the experimental observations at very low ingestion rates appeared to approach the origin, rather than (in the model) a positive $y$-intercept. Bochdansky \& Deibel (1997) suggested instead that the relationship between CBE activity and $I$ was better described by a Michaelis-Menten saturation equation, which, when fit to the experimental observations of Head \& Harris (1996), resulted in a higher $r^{2}$ value than the linear fit. They argued that the pattern of enzyme activity described by the Michaelis-Menten equation was compatible with the CBE activity being associated only with the copepods and not with the ingested phytoplankton. Head (1997), however, pointed out that when the data were transformed to show the relationship between $\% D$ and $I$, the curve generated using the Michaelis-Menten equation did not fit the experimental observations of Head \& Harris (1996), since it approached a value of $\% D$ of ca $60 \%$ at the $y$-intercept (zero ingestion rate), whereas experimental observations show $\% D$ values of $100 \%$ below some threshold value of $I$, as had been predicted by the linear fit.

In this paper, we will introduce a new model to describe the relationship between CBE activity and $I_{\text {, }}$ which incorporates elements of both the Head \& Harris (1996) and Bochdansky \& Deibel (1997) models. From the Head \& Harris (1996) model we have retained the concept of the presence of the 2 enzyme pools, whereas from the Bochdansky \& Deibel (1997) model we have incorporated the idea of using MichaelisMenten functions to describe the relationships between the activities of these enzymes and ingestion rate, the latter being used as a proxy for substrate concentration. We fitted this model to data collected during incubation experiments with copepods that had been feeding during pre-bloom (low surface chlorophyll, high surface nutrients) and early-bloom (intermediate surface chlorophyll, intermediate surface nutrients) conditions in the Labrador Sea. Our new model enabled us to test the hypothesis of Penry \& Frost (1991) that copepods acclimated to teeding at high concentrations (early-bloom copepods) have higher chl a destructive capacities than do those which have just started to feed in situ (pre-bloom copepods). In the experiments of Head \& Harris (1996), the overall relationship between $\% D$ and $I$ was apparently similar for copepods from pre-bloom, early-bloom and midbloom conditions in the Labrador Sea and Newfound- 
land Shelf regions. In their study, however, natural food was used in all incubations, so that the species assemblages and ranges of concentrations of food were not the same for each group of animals (e.g. pre-bloom copepods were fed only at low food concentrations). Degrees (\%D) and rates of chl a destruction (CBE activities) depend on ingestion rate (Penry \& Frost 1991. Head \& Harris 1996), which in turn depends on food type (as it affects filtration rates) and food concentration (Frost 1972). Thus, to demonstrate differences in the CBE activities between groups of copepods from different feeding backgrounds it is desirable to feed them a similar type of food (e.g. diatoms) over a standardized range of initial chl a concentrations, which is what we attempted to do in this study. In addition, we have also fitted our new model to the data of Head \& Harris (1996), for incubation experiments with copepods that had been feeding during mid - to latebloom (intermediate surface chlorophyll, low surface nutrients) conditions in situ.

\section{MATERIALS AND METHODS}

Sample collection. Seawater and copepods for incubation experiments were collected at 5 stations (P1, P2, P3, E1 and E2) in the Labrador Sea between 20 and 27 May 1996 (Fig. 1). The copepods were collected between $100 \mathrm{~m}$ and the surface using a $200 \mu \mathrm{m}$ mesh net towed vertically. At each station, 100 to $200 \mathrm{l}$ of seawater were collected at a depth other than the chlorophyll maximum, using a pump fitted with a Guideline ${ }^{\circ}$ CD and an in situ fluorometer, and later filtered through $0.2 \mu \mathrm{m}$ Gelman ${ }^{10}$ filters for use as filtered seawater (FSW) in experimental manipulations. Seawater samples for determination of particulate chlorophyll and nitrate concentrations in situ were taken using the pump.

Incubation experiments. The copepods were starved for approximately $3 \mathrm{~h}$ in FSW to ensure that their guts would be empty. They were then screened through a $780 \mu \mathrm{m}$ mesh, rinsed several times with FSW to remove adhering phytoplankton and any faecal pellets produced after capture, and divided into $100 \mathrm{ml}$ aliquots containing roughly equal numbers.

Table 1 summarizes the details of the experimental set-up and conditions for each of the 5 incubation experiments. At the start of each incubation, a $500 \mathrm{ml}$ sample and $3 \times 100 \mathrm{ml}$ sub-samples were taken from

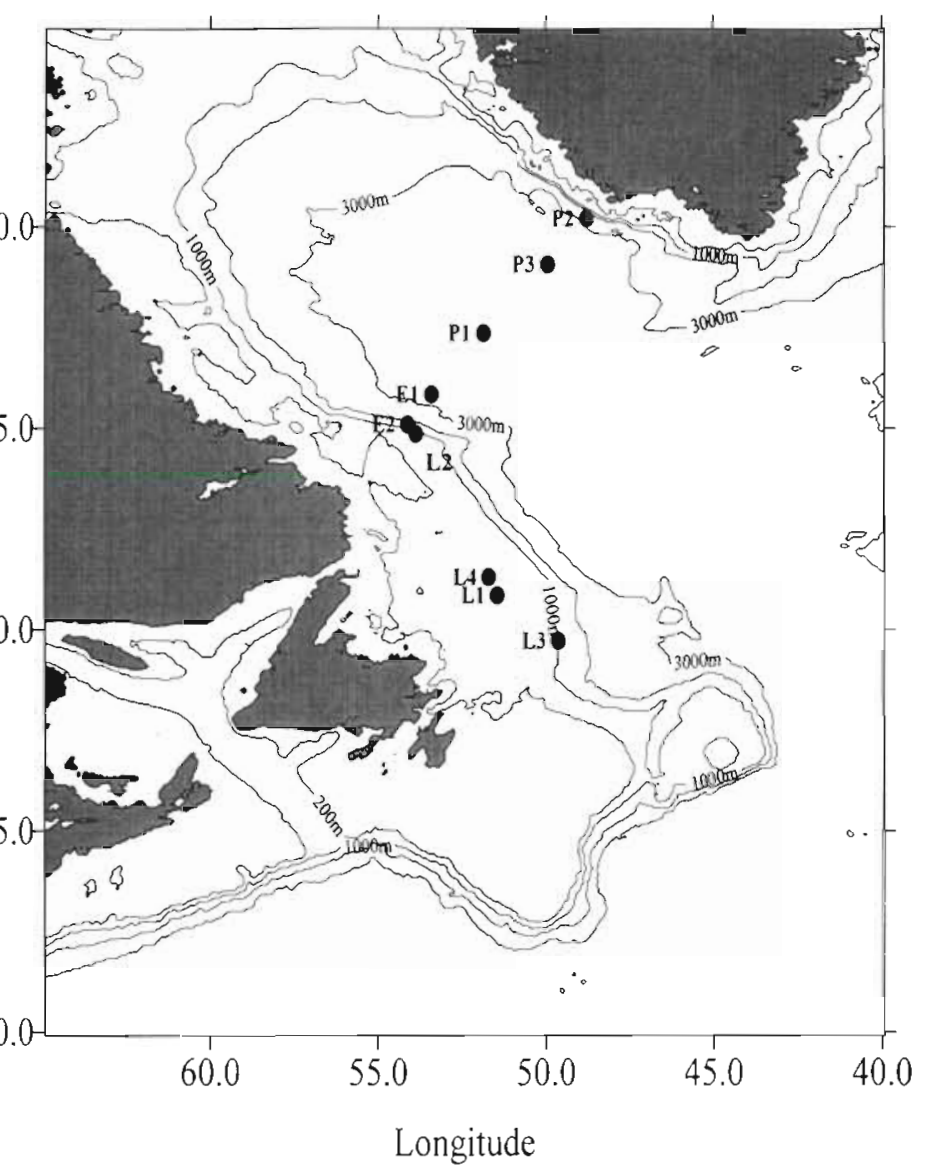

Fig. 1. Geographic locations of Stns P1 (22 May), P2 (24 May), P3 (25 May), E1 (20 May) and E2 (27 May), sampled in 1996; also shown are 4 stations previously described in Head \& Harris (1996): L1 (27 May 1994), L2 (5 June 1994), L3 (25 May 1992) and L4 (29 May 1992)

the initial-time $(t=0)$ control bottle(s). At the same time, the entire contents of the $t=0$ experimental bottles were filtered and the number of copepods collected on each of the filters was recorded. The finaltime $(t=f)$ bottles (control and experimental) were placed in a deck incubator from which light was excluded and through which surface seawater was running continuously. After approximately $10 \mathrm{~h}$, the $t=\mathrm{f}$ bottles were sampled in the same manner as the $t=0$ bottles had been.

Comparisons of pigment concentrations between $t=0$ and $t=\mathrm{f}$ control bottles allowed us to confirm that changes in pigment concentration due either to dark exposure or to microzooplankton grazing (for experiments in which in situ food was used) were insignificant during the incubations. These changes were monitored in both 'real-time', by fluorometric analysis of the $3 \times 100 \mathrm{ml}$ sub-samples, and later by high-performance liquid chromatography (HPLC) analysis of the $500 \mathrm{ml}$ sub-samples (see 'Sample analyses'). 
Table 1. Sampling dates, station positions, incubator temperatures and food types for incubation experiments P1, P2, P3 (pre-bloom conditions), E1 and E2 (early-bloom conditions) in the Labrador Sea

\begin{tabular}{|lcccl|}
\hline Expt & $\begin{array}{c}\text { Sampling } \\
\text { date } \\
(1996)\end{array}$ & $\begin{array}{c}\text { Station } \\
\text { position } \\
\text { (Labrador Sea) }\end{array}$ & $\begin{array}{c}\text { Incubator } \\
\text { temperature } \\
\left({ }^{\circ} \mathrm{C} \text { ) }\right.\end{array}$ & Food type \\
\hline P1 & $22 \mathrm{May}$ & $57^{\circ} 22^{\prime} \mathrm{N}, 51^{\circ} 51^{\prime} \mathrm{W}$ & - & Coscinosira sp. \\
P2 ${ }^{\mathrm{d}}$ & $24 \mathrm{May}$ & $60^{\circ} 12^{\prime} \mathrm{N}, 48^{\circ} 47^{\prime} \mathrm{W}$ & 3 & In situ phytoplankton \\
P3 & $25 \mathrm{May}$ & $59^{\circ} 04^{\prime} \mathrm{N}, 49^{\circ} 57^{\prime} \mathrm{W}$ & 5 & Thalassiosira sp. \\
E1 & $20 \mathrm{May}$ & $55^{\circ} 51^{\prime} \mathrm{N}, 53^{\circ} 24^{\prime} \mathrm{W}$ & 3 & Thalassiosira sp. \\
E2 & $27 \mathrm{May}$ & $55^{\circ} 06^{\prime} \mathrm{N}, 54^{\circ} 07^{\prime} \mathrm{W}$ & 3 & In situ phytoplankton \\
axperiments in which 2 experimental and 2 control bottles were used at \\
each food concentration (instead of 3 experimental and 1 control bottle)
\end{tabular}

in the control bottles were insignificant (no overall trends of negative or positive growth were evident, as shown by both the fluorometric and HPLCderived data), so that they did not need to be considered in these calculations. To derive ingestion rates, replicate initial chl a concentrations (at each of the 5 food concentrations) were averaged (replication was within $5 \%$ ) and multiplied by the filtration rates for the individual experimental bottles

Copepod species identification and biomass. For the determination of species compositions, a sample of

The $3 \times 100 \mathrm{ml}$ sub-samples taken from the control bottles were filtered onto $25 \mathrm{~mm}$ Whatman ${ }^{\text {(1) }} \mathrm{GF} / \mathrm{C}$ filters, extracted immediately with $90 \%$ acetone and stored at $-20^{\circ} \mathrm{C}$ overnight. All other samples were collected on $47 \mathrm{~mm}$ Whatman ${ }^{\otimes} \mathrm{GF} / \mathrm{C}$ filters, folded inside cryovials, and zrozen in liquid nitrogen for subsequent HPLC analysis.

The phytoplankton cultures (i.e. Thalassiosira sp. and Coscinosira sp.) were grown in semi-continuous culture in $\mathrm{f} / 2$ medium at $10^{\circ} \mathrm{C}$ and their chlorophyll concentrations were measured most days (see 'Sample analyses') to ensure that they were actively growing

Sample analyses. Determinations of chlorophyll at sea (in situ, control bottles, cultures) were made using a Turner Designs fluorometer (Model 10-aU) according to the method of Yentsch \& Menzel (1963). Nitrate concentrations were measured using an Alpkem Autoanalyzer (Model RFA 300)

The frozen filters resulting from the experiments (from both the control and experimental bottles) were removed from liquid nitrogen when the ship returned to port and stored in a cryogenic freezer $\left(-70^{\circ} \mathrm{C}\right)$ until analysis using HPLC, which was within 6 mo of their collection. Identification and quantification of individual pigments by HPLC, using known standards, was as described by Head \& Horne (1993). Concentrations of chl a equivalents (chl $a+c h l$ a allomers and epimers + chlorophyllide a), chl $c\left(c_{1}, c_{2}\right.$ and $\left.c_{3}\right)$ and the carotenoids were quantified using absorbance calibration factors. Concentrations of a-type phaeopigments were calculated using fluorescence calibration factors. Concentrations of a-type phaeopigments were reported as their respective chl a equivalent concentrations ( $\mu \mathrm{g}$ chl a equiv. $\mathrm{I}^{-1}$ ), whereas all other pigments were reported as $\mu \mathrm{g}$ pigment $\mathrm{l}^{-1}$

Filtration rates and ingestion rates. Copepod filtration and ingestion rates were calculated over the incubation periods using the equations of Frost (1972), where ingestion rates were based on changes in chl a concentrations between the $t=0$ and $t=\mathrm{f}$ experimental bottles. Changes in chlorophyll concentrations screened $(>780 \mu \mathrm{m}$ ) experimental copepods from each station was stored in 5\% formalin until analysis. (Note: at Stn E2, the sample was not screened at $780 \mu \mathrm{m}$ ). Over 100 copepods were identified to copepodite stage and species using a Zeiss binocular dissecting microscope and a $10 \mathrm{ml}$ circular counting chamber. Calanus spp. were distinguished from each other on the basis of size (e.g. all copepodite stages of C. hyperboreus are much larger than those of either $C$ glacialis or $C$. finmarchicus and $C$. glacialis is ca 15 to $20 \%$ larger than C. finmarchicus).

For the determination of biomass, up to 30 individuals of each copepodite stage of each species were placed on Teflon sheets in glass Petri dishes and dried for at least $24 \mathrm{~h}$ at $60^{\circ} \mathrm{C}$ (Fisher Isotemp Oven). They were then weighed using a Cahn microbalance (Model $\mathrm{C}-31$ ) to yield an average biomass in milligrams dry weight for each copepodite stage of each species present. The biomass of each group of copepods present in each experiment was then calculated using these dry weights and the copepod counts.

$\mathrm{Chl}$ a destruction. Degrees of $\mathrm{chl}$ a destruction $\% \mathrm{D}$, the proportion of chl a ingested that is not recovered as phaeopigment) were calculated by comparing the concentration of chl a equivalents consumed with the concentration of a-type phaeopigments produced in the incubation bottles, using the following expression:

$$
\% D=\left\{1-\left[\left(P_{\mathrm{f}}-P_{0}\right) /\left(C_{0}-C_{\mathrm{t}}\right)\right]\right\} \cdot 100
$$

where $P_{0}$ and $P_{\mathrm{f}}$ represent the total phaeopigment concentrations at $t=0$ and $t=\mathrm{f}$, and $C_{0}$ and $C_{t}$ represent the chl a concentrations at $t=0$ and $t=\mathrm{f}$.

\section{RESULTS}

\section{Physical properties of the water column}

Stns P1, P2 and P3 showed pre-bloom conditions: at the surface of the water column, particulate 
chlorophyll concentrations were rela-

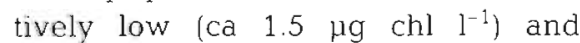
nitrate concentrations relatively high (ca $9.9 \mu \mathrm{g}$-at $\mathrm{1}^{-1}$ ). Early-bloom conditions prevailed at Stns E1 and E2, with intermediate concentrations of both particulate chlorophyll (ca $5.9 \mu \mathrm{g} \mathrm{chl} \mathrm{^{-1 }}$ ) and nitrate (ca $7.5 \mu \mathrm{g}$-at $\mathrm{I}^{-1}$ ) at the surface. The water columns at Stns L1 and L2 (Fig. 1), described by Head \& Harris (1996) as midbloom, are referred to here as showing late-bloom conditions: surface concentrations of chlorophyll were in-

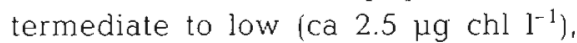
with the chlorophyll maximum found above $20 \mathrm{~m}$, and surface nitrate concentrations were near zero. At Stns L3 and L4 (Fig, 1), also described by Head \& Harris (1996), no in situ concentrations of nitrate and particulate chlorophyll were determined. Based on the hydrographic conditions at Stns L1 and L2, which were sampled in the same general region at roughly the same time of year, we assume that late-bloom conditions also prevailed at Stns L3 and L4.
Table 2. Species composition of copepods $(>780 \mu \mathrm{m})$ and copepodite stage composition of Calanus spp. at Stns P1, P2, P'3 (pre-bloom conditions), E1 and E2 (early-bloom conditions) in the Labrador Sed

\begin{tabular}{|c|c|c|c|c|c|}
\hline Expt & & Calanus & Calanus & Calanus & Other \\
\hline P1 & $\begin{array}{l}\% \text { of all copepods } \\
\% \text { species at stage: } \\
\text { CVIF } \\
\text { CVIM } \\
\text { CV } \\
\text { CIV }\end{array}$ & $\begin{array}{r}94 \\
89 \\
2 \\
8 \\
1\end{array}$ & 0 & $\begin{array}{r}2 \\
0 \\
0 \\
67 \\
33\end{array}$ & 4 \\
\hline $\mathrm{P} 2$ & $\begin{array}{l}\% \text { of all copepods } \\
\% \text { species at stage: } \\
\text { CVIF } \\
\text { CV } \\
\text { CIV } \\
\text { CIII } \\
\text { CII }\end{array}$ & $\begin{array}{r}89 \\
88 \\
11 \\
1 \\
0 \\
0\end{array}$ & $\begin{array}{r}1 \\
0 \\
0 \\
100 \\
0 \\
0\end{array}$ & $\begin{array}{r}10 \\
0 \\
19 \\
50 \\
25 \\
6\end{array}$ & 0 \\
\hline P3 & $\begin{array}{l}\% \text { of all copepods } \\
\% \text { species at stage: } \\
\text { CVIF } \\
\text { CVIM } \\
\text { CV } \\
\text { CIV }\end{array}$ & $\begin{array}{r}90 \\
63 \\
5 \\
28 \\
4\end{array}$ & 0 & $\begin{array}{r}3 \\
33 \\
0 \\
33 \\
33\end{array}$ & 7 \\
\hline $\begin{array}{l}E 1 \text { and } \\
E 2^{\circ}\end{array}$ & $\begin{array}{l}\% \text { of all copepods } \\
\% \text { species at stage: } \\
\text { CVIF } \\
\text { CVIM } \\
\text { CV } \\
\text { CIV }\end{array}$ & $\begin{array}{r}90 \\
91 \\
2 \\
6 \\
2\end{array}$ & 0 & $\begin{array}{r}3 \\
0 \\
0 \\
100 \\
0\end{array}$ & 7 \\
\hline
\end{tabular}

\section{Copepod species composition and phytoplankton pigment composition}

At each station, approximately $90 \%$ of all copepods (>780 $\mu \mathrm{m})$ were Calanus finmarchicus (>60\% females; Table 2). Calanus hyperboreus, C. glacialis and other copepods (Oithona sp., Euchaeta spp., Metridia spp.) made up the remainder of the total number (Table 2).

The pigment compositions of the 2 diatom cultures, Thalassiosira sp. (Expts P3 and E1) and Coscinosira sp. (Expt P1), were very similar and both compositions were typical of diatoms (Jeffrey et al. 1997; Table 3). The in situ phytoplankton used as food in Expt P2 contained chl $c_{3}$ and 19-hexanoyloxyfucoxanthin (Table 3), both of which occur in prymnesiophytes. Microscopic observations of surface seawater showed that large Phaeocystis spp. colonies were dominant: Phaeocystis spp. is a colonial prymnesiophyte previously found in this region (Head \& Harris 1996). The in situ phytoplankton used as food in Expt E2 had a pigment composition similar to that of the diatom cultures (Table 3). Microscope counts showed that diatoms were dominant and that Thalassiosira spp. and Fragilaria oceania were the most abundant species (W. K. W Li pers. comm.).
Table 3. Concentrations ( $\mathrm{g} \mathrm{I}^{-1}$ ) of each individual pigment (listed in order of increasing retention time) in the phytoplankton fed to copepods (on the $t=0$ control filter at the highest food concentration) in Expt P1 (Coscinosira sp.), P2 (in situ phytoplankton), P3 (Thalassiosira sp.), E1 (Thalassiosira sp.) and E2 (in situ phytoplankton). nd: not detectable

\begin{tabular}{|c|c|c|c|c|c|}
\hline Pigment & P1 & $\mathrm{P} 2$ & P3 & E1 & E2 \\
\hline $\mathrm{Chl} c_{3}$ & nd & 0.02 & nd & nd & nd \\
\hline Chlorophyllide a & nd & nd & 0.51 & 0.44 & 0.15 \\
\hline$C_{1} c_{1}$ and $c_{2}$ & 1.67 & 0.17 & 3.96 & 3.01 & 2.67 \\
\hline Phaeophorbide a & nd & nd & nd & nd & 0.31 \\
\hline Fucoxanthin & 5.90 & 0.33 & 10.90 & 9.18 & 7.21 \\
\hline 19-Hexanoyloxyfucoxanthin & in nd & 0.05 & nd & nd & nd \\
\hline Pyrophaeophorbide a & nd & nd & nd & nd & 0.61 \\
\hline Diadinoxanthin & 0.48 & nd & 0.80 & 0.72 & 0.51 \\
\hline Diatoxanthin & 0.02 & nd & 0.01 & 0.06 & 0.05 \\
\hline Chl a allomer & 0.46 & nd & 3.06 & 0.22 & 3.18 \\
\hline Chl a & 13.48 & 0.99 & 15.19 & 15.09 & 15.11 \\
\hline Chl a epimer & nd & nd & nd & nd & 0.62 \\
\hline Phaeophytin a & 0.13 & nd & 0.13 & 0.10 & 0.27 \\
\hline$\beta$-carotene & 0.27 & nd & 0.44 & 0.37 & 0.25 \\
\hline Pyrophaeophytin a & nd & nd & nd & nd & nd \\
\hline $\begin{array}{l}\text { Total pigment } \\
\text { concentration }\end{array}$ & 22.42 & 1.56 & 35.01 & 29.19 & 30.92 \\
\hline
\end{tabular}




\section{Copepod feeding rates}

The filtration rates of the copepods appeared to depend on the type of food they were consuming (Table 4) Copepods from pre-bloom conditions filtered Coscinosira sp. (Expt P1) most rapidly, the in situ Phaeocystis sp. (Expt P2) less so and Thalassiosira sp. (Expt P3) least rapidly. Copepods collected from early-bloom conditions filtered in situ diatoms (Expt E2) and Thalassiosira sp. (Expt E1) at similar rates. Early-bloom copepods filtered a given volume of Thalassiosira sp. about 1.6 times faster (2-sample t-test, $\alpha=0.05, p<0.01$ ) than did pre-bloom copepods (Table 4), indicating that the former animals were more physiologically active (cf. Runge 1980). Ingestion rates of copepods in al. experiments increased with. increasing initial chl a concentrations and did not appear to saturate at high food concentrations (Fig 2).

\section{Phaeopigment production and $\mathrm{chl}$ a destruction}

The only phaeopigments produced by the copepods in any of the experiments were pyrophaeophorbide a and pyrophaeophytin a. Chromatograms from Expt P1 are shown as an example (Fig. 3). At $t=0$, no phaeophorbide a (peak 4), pyrophaeophorbide a (peak 7) or pyrophaeophytin a (peak 14) were detected in the experimental bottles. At $t=\mathrm{f}$, both pyrophaeophorbide a and pyrophaeophytin a were detected, but there was still no phaeophorbide a. Although some phaeophytin a (peak 12) was detected at $t=0$, roughly the same amount was there at $t=\mathrm{f}$. There were marked decreases in the heights of the chl $a_{\text {, fucoxanthin, }}$ chl $c_{1}$ and $c_{2}$ and $c h l a$ allomer peaks between $t=0$ and $t=f$, and smaller decreases in the peak heights of diadinoxanthin and $\beta$-carotene

Table 4. Mean copepod dry weights, copepod densities, range of initial chl a concentrations $\left(C_{0}\right)$, incubation times $(t)$ and filtration rates $(F$, followed by $1 \mathrm{SD}$ and sample size in brackets) for Expts P1, P2, P3 (pre-bloom conditions), E1 and E2 (early-bloom conditions) in the Labrador Sea

\begin{tabular}{|c|c|c|c|c|c|}
\hline Expt & $\begin{array}{l}\text { Copepod dry } \\
\text { weight } \\
\text { (mg ind } .^{-1} \text { ) }\end{array}$ & $\begin{array}{l}\text { Copepod } \\
\text { density } \\
\text { (ind. } 1^{-6} \text { ) }\end{array}$ & $\begin{array}{c}C_{6} \\
\left(\mu g \operatorname{chl}^{-1} l^{-1}\right)\end{array}$ & $\begin{array}{c}t \\
(h)\end{array}$ & $\begin{array}{c}F \\
\left(\mathrm{ml} \text { ind }{ }^{-1} \mathrm{~h}^{-1}\right)\end{array}$ \\
\hline P1 & 0.41 & 33.0 & $2.23-13.91$ & 8.76 & $5.32 \pm 1.43(15)$ \\
\hline P2 & 0.30 & 18.5 & $0.34-1.36$ & 8.83 & $2.19 \pm 0.79(10)$ \\
\hline P3 & 0.70 & 28.5 & $2.75-17.90$ & 8.55 & $0.64^{\prime \prime} \pm 0.30(15)$ \\
\hline E1 & 0.37 & 21.8 & $0.95-13.70$ & 9.26 & $1.01^{\mathrm{d}} \pm 0.36(14)$ \\
\hline E2 & $0.37^{h}$ & 11.7 & $4.42-21.30$ & 12.47 & $1.66 \pm 0.71(15)$ \\
\hline
\end{tabular}

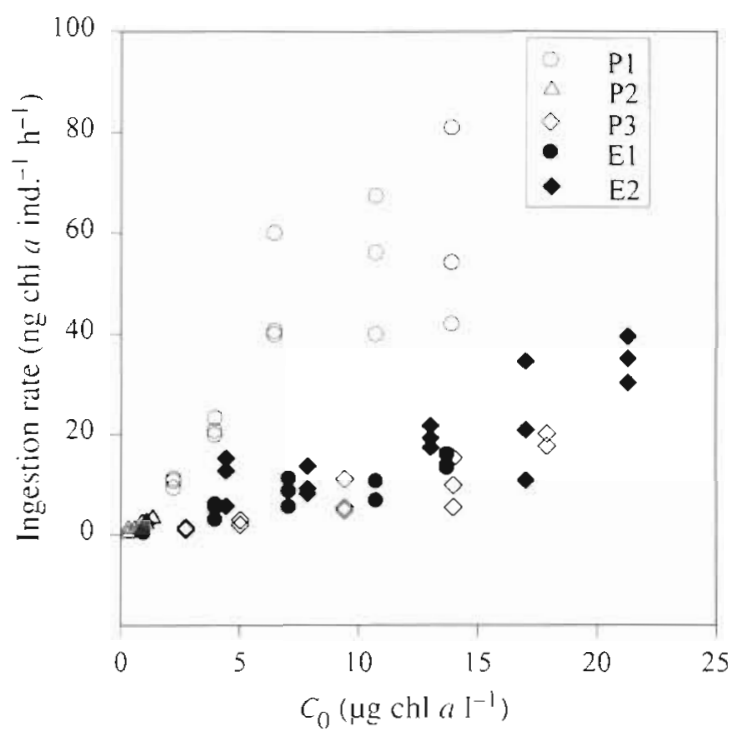

Fig. 2. Ingestion rates (ng chi a ind.-1 $\mathrm{h}^{-1}$ ) of copepods in Expts P1, P2, P3, E1 and E2 over a range of initial chl a concentrations $\left(C_{n}, \mu g\right.$ chl is $\left.1^{-1}\right)$

For the pre-bloom experiments (Expts P1, P2 and P3), the rates of chl a destruction (i.e. CBE activity), calculated as in Head \& Harris (1996), ranged between 0.3 and 23.1. ng chl a bleached ind. ${ }^{-1} \mathrm{~h}^{-1}$ (Fig 4a). As found by Head \& Harris (1996), CBE activity increased with ingestion rate (I). Degrees of chl a destruction ranged between 1.1 and $100 \%$ (Fig. 4b). (Note: logically, copepods cannot destroy more that $100 \%$ of the chl a they ingest, so values of $\% D$ greater than $100 \%$, which were probably the result of analytical or sampling errors, were set to $100 \%$. In fact, only $10 \%$ of all estimates of $\% D$ were adjusted in this way, and most [ca $70 \%$ ] of these values were between 100 and $125 \%$ before adjustment.) The relationship between $\% D$ and $I$ was inverse but non-linear, as found by Head \& Harris (1996), so that when copepods collected at pre-bloom stations ingested food slowly, degrees of chl a destruction were highest and they were lower when the copepods ingested at higher rates (Fig $4 \mathrm{~b}$ ). CBE activities ranged between 0.5 and $14.3 \mathrm{ng}$ chl a bleached ind.$^{-1} h^{-1}$ for the early-bloom Expts E1 and E2 (Fig 5a). As with the pre-bloom data, CBE activity increased with ingestion rate. Degrees of chl a destruction varied between 46.7 and $100 \%$ and the same pattern was observed here as for the prebloom experiments: more chl a was destroyed at low than at high ingestion rates (Fig. 5b) 

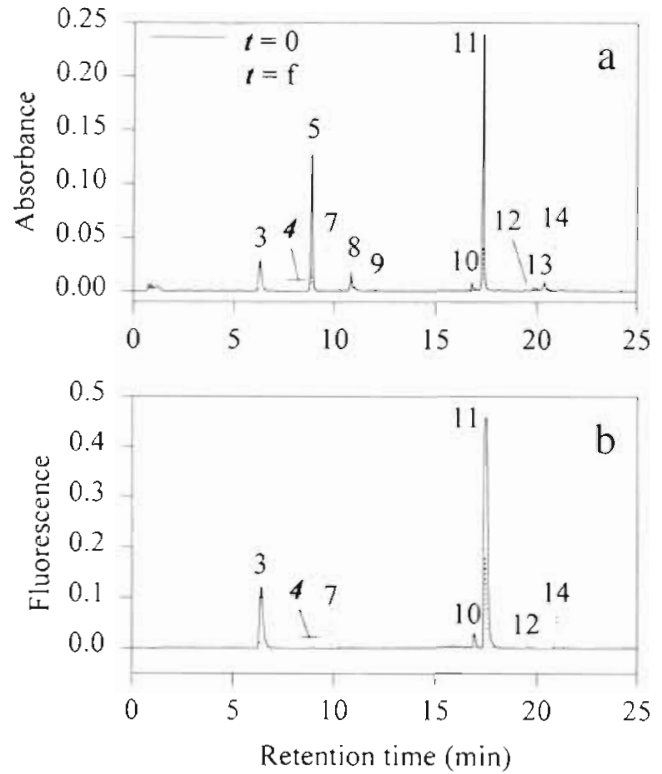

Fig. 3. (a) Absorbance and (b) fluorescence chromatograms of pigments in experimental bottles before $(t=0)$ and after $(t=f)$ grazing by copepods on Coscinosira sp. (Expt P1). Identified peaks: (3) chl $c_{1}$ and $c_{2}$, (5) fucoxanthin, (7) pyrophaeophorbide $a,(8)$ diadinoxanthin, (9) diatoxanthin, (10) chl $a$ allomer,

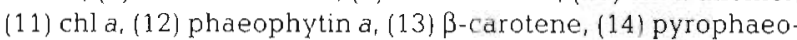
phytin a. ' 4 ' and pointer indicate where phaeophorbide $a$ would normally appear
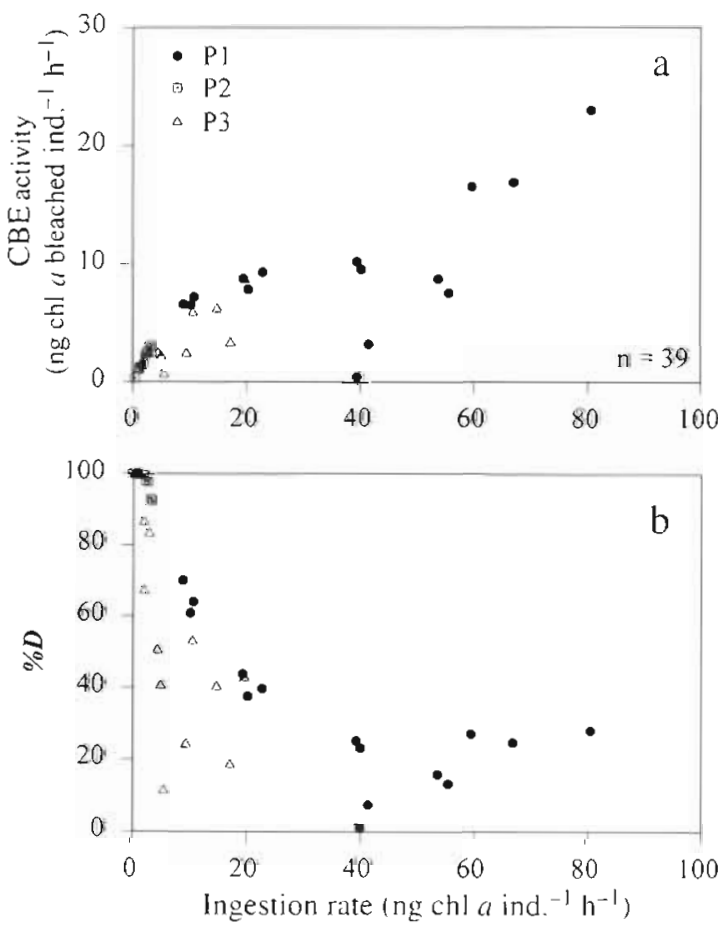

Fig. 4. Relationship between (a) CBE activity (ng chl a bleached ind.$^{-1} \mathrm{~h}^{-1}$ ) and ingestion rate (ng chl $\mathrm{a}$ ind $\left.{ }^{-1} \mathrm{~h}^{-1}\right)$, and (b) the degree of chl a destruction $(\% D)$ and ingestion rate (ng chl $a$ ind ${ }^{-1} \mathrm{~h}^{-1}$ ) for pre-bloom Expts P1, P2 and P3
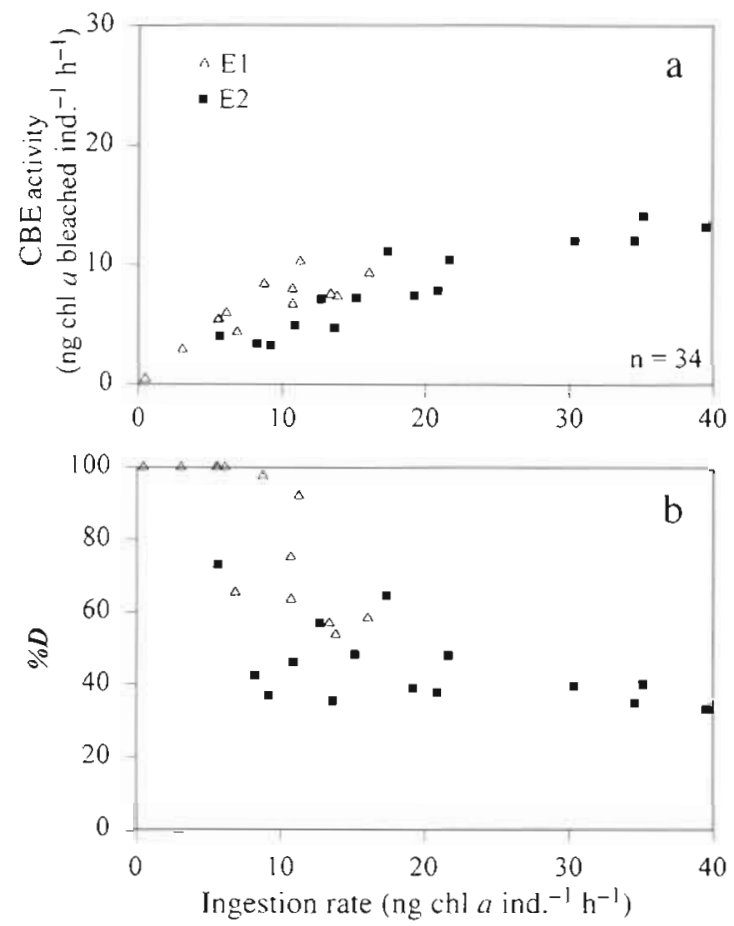

Fig. 5. Relationship between (a) CBE activity (ng chl a bleached ind.$^{-1} \mathrm{~h}^{-1}$ ) and ingestion rate (ng chl $a$ ind ${ }^{-1} \mathrm{~h}^{-1}$ ), and (b) the degree of chl a destruction $(\% D)$ and ingestion rate (ng chl $a$ ind.$^{-1} \mathrm{~h}^{-1}$ ) for early-bloom Expts E1 and E2

\section{DISCUSSION}

\section{Modeling the kinetics of chl a destruction}

The linear model of Head \& Harris (1996) appeared to fit the pre-and early-bloom data presented here relatively well (Fig. 6) and in both cases the straight lines derived from the regressions of $C B E$ activity against $I$ had positive slopes and positive $y$-intercepts. As was pointed out by Bochdansky \& Deibel (1997) for a previous data set (Head \& Harris 1996), however, despite the overall apparent fit $\left(\mathrm{r}^{2}=\right.$ 0.70 and 0.76 ), CBE activity was poorly described at low values of $I$, where the experimental observations approached the origin and the line gave a positive intercept. Nevertheless, when these straight lines were transformed to describe the relationships between $\% D$ and $l$, the derived curves again appeared to fit the experimental data quite well and, as reported by Head \& Harris (1996), each gave a threshold ingestion rate below which all ingested chl a was destroyed during grazing The curves appeared to tend to a limit at high ingestion rates (ca 25 and $40 \%$ destruction for the pre-bloom and early-bloom cases, respectively), where Head \& Harris (1996) would argue that phytoplankton enzymes destroyed most of the ingested chl a. 

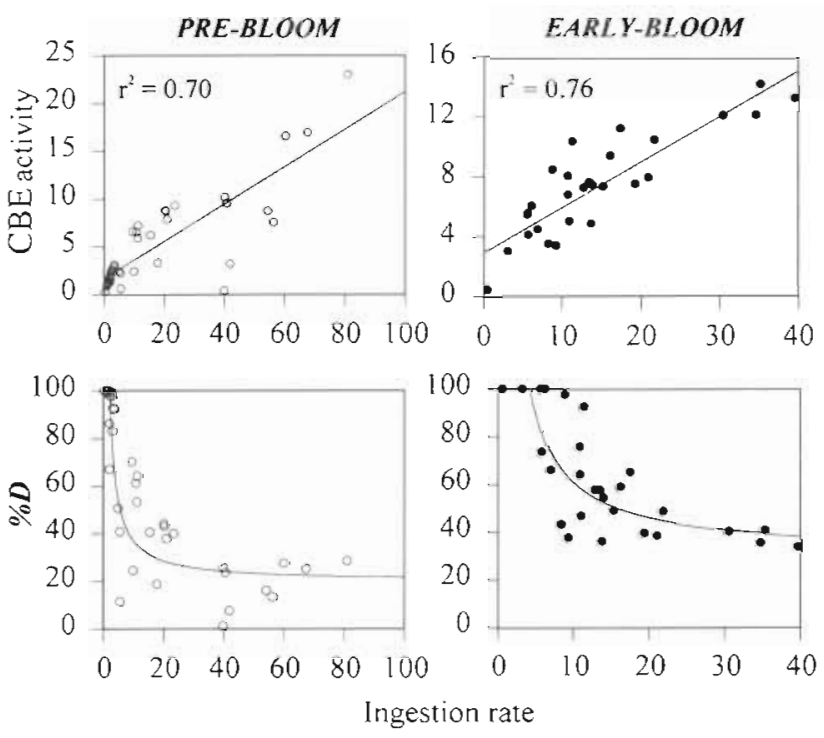

Fig. 6. A linear function fitted to pre-bloom Expts P1, P2 and P.3 (left column) and to early-bloom Expts E1 and E2 (right column) showing the relationships between CBE activity (ng chl $a$ bleached ind ${ }^{-1} h^{-1}$ ) and ingestion rate (ng chl $a$ ind.-1 $\mathrm{h}^{-1}$ ) (upper panels) and between the degree of chl a destruction (\%D) and ingestion rate (ng chl a ind ${ }^{-1} \mathrm{~h}^{-1}$ ) (lower panels)

According to the suggestion of Bochdansky \& Deibel (1997), we also fitted a Michaelis-Menten equation to the results (Fig. 7). For the relationships between CBE activity and $I$, with the pre-and early-bloom copepods,
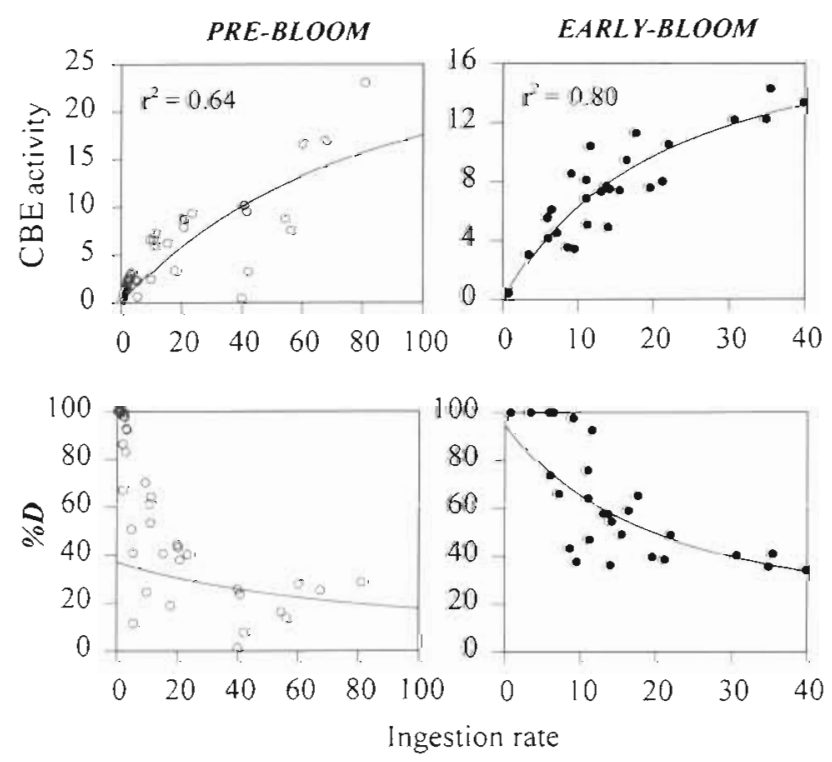

Fig. 7. A Michaelis-Menten function fitted to pre-bloom Expts P1, P2 and P3 (left column) and to early-bloom Expts E1 and E2 (right column) showing the relationships between CBE activity (ng chl a bleached ind ${ }^{-1} \mathrm{~h}^{-1}$ ) and ingestion rate (ng chl $a$ ind. ${ }^{-1} h^{-1}$ ) (upper panels) and between the degree of chl a destruction $(\% D)$ and ingestion rate (ng chl $a$ ind ${ }^{-1} \mathrm{~h}^{-1}$ ) (lower panels) the Michaelis-Menten fit gave $r^{2}$ values that were lower and higher, respectively, than those obtained using linear fits. This equation described CBE activity at low values of $I$ better than did the straight line. However, as shown by Head (1997), when the MichaelisMenten functions were transformed to describe the relationship between $\% D$ and $I$, the derived curves did not fit either set of experimental observations.

Since each of the 2 models had features in its favour, we decided to test a new model that would incorporate elements of them both. In this new model we tollowed the argument of Head \& Harris (1996) that there are 2 pools of CBE activity (one derived from the copepods and one from the phytoplankton), and the argument of Bochdansky \& Deibel (1997) that Michaelis-Menten functions are appropriate for the description of enzyme kinetics. Thus, in our new 'double Michaelis-Menten model' we have expressed CBE activity" as the sum of 2 Michaelis-Menten expressions: one for each of the 2 pools of enzyme. The form of the double MichaelisMenten model' is as follows

$\mathrm{CBE}$ activity $=$

$\left[\left(V_{\max }^{\mathrm{c}} \cdot I\right) /\left(K^{\mathrm{c}}+I\right)\right]+\left[\left(R_{\max }^{\mathrm{p}} \cdot I\right) /\left(K^{\mathrm{p}}+I\right)\right] \cdot I$

It is important to note, however, that these expressions are somewhat different from those commonly used to describe the relationship between the rate of reaction of an enzyme and its substrate concentration. In our new equation $I$ is used as a proxy for substrate concentration, and indeed it is not unreasonable to suppose that the concentration of chl $a$ in the copepod foregut should be related to the rate at which it is being ingested, but the units of $I$ are ng chl $a$ ind..$^{-1} \mathrm{~h}^{-1}$. Thus, in these expressions, $K^{\mathrm{c}}$ and $K^{\mathrm{p}}$, which represent the half-saturation constants of the copepod and phytoplankton $C B E$, respectively, also have units of ng chl a ind.$^{-1} h^{-1}$, i.e. they are the ingestion rates at which each of the enzymes operates at one half its maximum velocity. The interpretation of the model is that the first Michaelis-Menten expression describes the CBE activity associated with the copepods and the second describes the CBE activity associated with the ingested phytoplankton. The concentration of the copepod CBE (i.e. $V_{\text {max }}^{c}$ ) does not change with the amount of food ingested (for which $I$ is a proxy) and the units of $V_{\text {max }}^{c}$ are ng chl a bleached ind ${ }^{-1} h^{-1}$. By contrast, the concentration in the copepod of the CBE associated with the ingested phytoplankton does vary with the amount of phytoplankton ingested, so that the units of $R_{\max }^{p}$ are (ng chl a bleached ind.$^{-1} \mathrm{~h}^{-1}$ ) . (ng chl a ingested ind.$^{-1} \mathrm{~h}^{-1}$ ), which is actually a dimensionless ratio. This parameter $\left(R_{\max }^{p}\right)$ we will term a 'CBE activity coefficient', rather than a maximum reaction rate, and it is an index of the level of endogenous CBE in the ingested phytoplankton. Thus, a high value of $R_{\max }^{p}$ in a given 
phytoplankton food indicates that it has a high endogenous level of $\mathrm{CBE}$ and a high capacity for destroying its own chl a.

The new model simplifies to the linear model of Head \& Harris (1996) at values of I above which both enzymes are operating at their maximum rates, and total CBE activity tends to the origin as I tends to zero (Fig. 8). When the new model was fitted to the pre-and early-bloom relationships between CBE activity and $I$ (Fig. 8), $r^{2}$ values were slightly higher than those for either the linear model of Head \& Harris (1996; Fig 6) or the single Michaelis-Menten function (Fig 7) suggested by Bochdansky \& Deibel (1997). An important additional aspect of the new model, however, is that when transformed to describe the relationship between $\% D$ and $I$, the derived curves appear to fit the experimental data (Fig. 8).

The new 'double Michaelis-Menten model' was also fitted to the data from Head \& Harris (1996) for experiments in which Calanus spp. sampled under latebloom conditions were fed natural assemblages of phytoplankton in vitro (Fig. 9). The relationship between CBE activity and $I$ was well fitted by the new model $\left(r^{2}=0.82\right)$ and the transformed curve also appeared to describe the relationship between \%D and $I$ adequately.

The maximum activities of the copepod CBEs ( $V_{\text {max }}^{c}$ ) for the pre-bloom and early-bloom cases were $2.78 \mathrm{ng}$ chl a bleached ind. ${ }^{-1} h^{-1}$ and $6.14 \mathrm{ng}$ chl a bleached
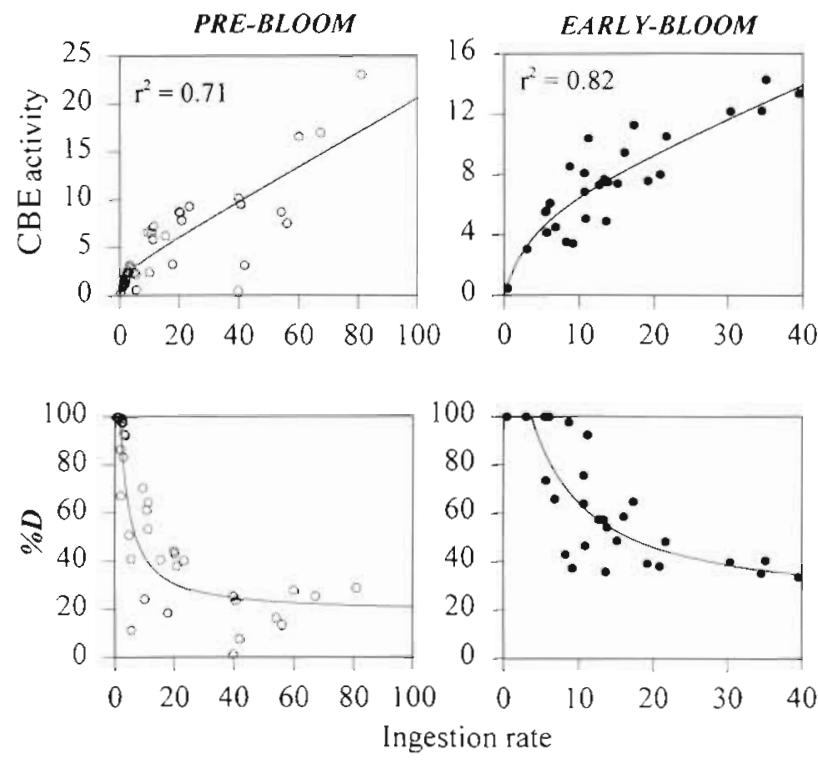

Fig. 8. A 'double Michaelis-Menten model' fitted to prebloom Expts P1, P2 and P3 (left column) and to early-bloom Expts $E 1$ and E2 (right column) showing the relationships between CBE activity (ng chl a bleached ind. ${ }^{-1} \mathrm{~h}^{-1}$ ) and ingestion rate (ng chl $\alpha$ ind ${ }^{-1} h^{-1}$ ) (upper panels) and between the degree of chl a destruction (\%D) and ingestion rate (ng chl a ind ${ }^{-1} h^{-1}$ ) (lower panels)
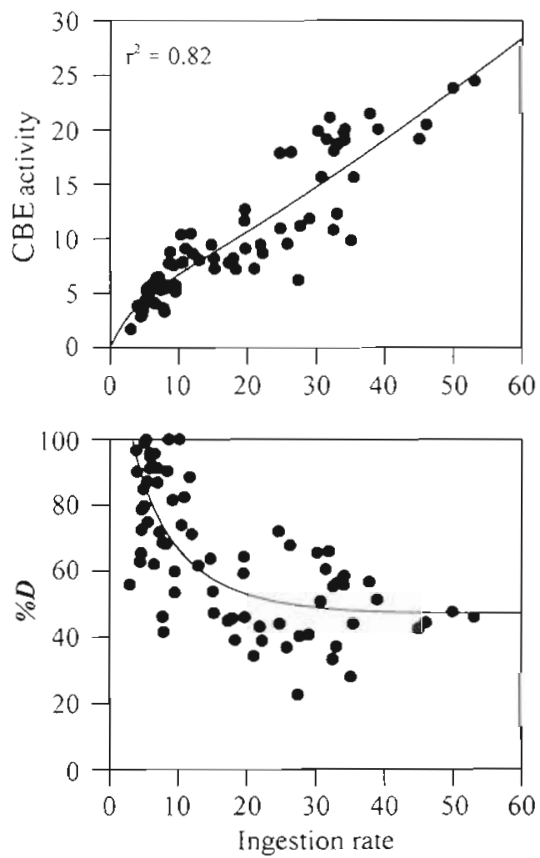

Fig. 9. The 'double Michaelis-Menten model' fitted to the late-bloom data of Head \& Harris (1996) showing the relationships between CBE activity ( $\mathrm{ng}$ chl a bleached ind ${ }^{-1} \mathrm{~h}^{-1}$ ) and ingestion rate (ng chl $a$ ind. ${ }^{-1} \mathrm{~h}^{-1}$ ) (upper panel) and between the degree of chl a destruction (\%D) and ingestion rate (ng chl $a$ ind.$^{-1} \mathrm{~h}^{-1}$ ) (lower panel)

ind. ${ }^{-1} \mathrm{~h}^{-1}$, respectively (Table 5). Assuming that the destructive capacity of the copepods varies with their $V_{\text {max }}^{c}$ values, and given that the copepod species and stages did not change, then these results are consistent with the hypothesis of Penry \& Frost (1991) that copepods acclimated to feeding at high ingestion rates (e.g. early-bloom animals) destroy more ingested chl a than do those acclimated to feeding at low ingestion rates (or those that have not yet been exposed to high food concentrations; e.g. pre-bloom animals). It should be noted, however, that the standard errors on these estimates are large enough that we cannot say with certainty that the values were actually different.

The activity coefficients of the phytoplankton CBEs $\left(R_{\max }\right)$ for the pre-bloom and early-bloom experiments were 0.18 and 0.22 (ng chl a bleached) - (ng chl $a$ ingested) ${ }^{-1}$, respectively (Table 5 ). These values are very similar, which is what one would expect if the ingested phytoplankton had more-or-less the same endogenous CBE level in all experiments. In fact, the copepods were feeding on diatoms in all experiments except in Expt P2, during which they fed on an in situ mixture dominated by Phaeocystis $\mathrm{sp}$. In this latter case, however, the food was always at very low concentrations so that any difference between the CBE activity coefficient of Phaeocystis sp. and that of 
diatoms probably would not have been noticed, because the estimate of its value over all 3 experiments would have been determined primarily by the values of CBE activity at high ingestion rates (i.e. for copepods feeding on diatoms). It is known that when diatoms are homogenized, some proportion of their chl a may be destroyed (Owens \& Falkowski 1982), presumably by endogenous enzymes, and it is possible that this destructive capacity of diatoms increases when they become senescent (Spooner et al. 1994). In our experiments, however, we used either actively growing cultures or natural diatoms which were probably also growing actively in situ, since they were collected from near-surface depths where nitrate concentrations and light levels were high. Thus, it is perhaps not surprising that CBE activity coefficients ( $R_{\max }^{p}$ values) were rather consistent throughout all our experiments.

Estimates of $V_{\max }^{c}$ and $R_{\max }^{\mathrm{m}}$ derived by fitting the new model to the data of Head \& Harris (1996) were both higher than for either value in the pre-and early-bloom cases (Table 5). $V_{\max }^{\mathrm{c}}$ was $8.67 \mathrm{ng} \mathrm{chl}$ a bleached ind. ${ }^{-1} \mathrm{~h}^{-1}$ and $R_{\text {max }}^{p}$ was 0.55 (ng chl a bleached) ( (ng chl a ingested $)^{-1}$. The copepod species and stage compositions were not very different in the Head \& Harris (1996) study from those in the present study. Thus, it is possible that the copepods may have had these slightly higher $V_{\max }^{c}$ values because they had been feeding in situ at high ingestion rates for a longer period of time than had the copepods used in the present study: the spring-bloom was evidently more advanced at Stns L1 and L2 than at either the P or E series of this study and this explanation would certainly be consistent with the hypothesis of Penry \& Frost (1991). The observation that the CBE activity coefficient in the phytoplankton (i.e. $R_{\text {max }}^{p_{\text {mas }}}$ ) was also higher in the Head \& Harris (1996) study might also be attributable to the state of the spring-bloom, if the phytoplankton were in fact in decline (due to the lack of nutrients), since Spooner et al. (1994) have shown that diatoms can destroy much of their own chl a when they become senescent. It should be noted, however, that the standard errors on these estimates of $V_{\max }^{c}$ and $R_{\text {max }}^{r}$ were high, so that the differences are perhaps more apparent than real.

We have not discussed our model estimates of the values of $K^{\mathrm{r}}$ and $K^{\mathrm{p}}$ or changes in them. This is because the errors associated with them were very large (Table 5). In fact, imprecise determinations of these parameters are inevitable. One reason is that they must be determined from estimates of CBE activity at very low ingestion rates. During the course of an incubation, initially low ingestion rates will decrease, but only slightly, as chl a concentrations decrease, whereas CBE activities and degrees of chl a destruction are likely to change to a much greater degree.
Thus, the high variability in the data at low ingestion rates is predictable (Figs. $8 \& 9$ ). In addition, at low ingestion rates the 2 enzymes (or enzyme systems) from the 2 different pools (copepods vs phytoplankton) may be competing for the substrate, in which case their combined activity is not appropriately described as the sum of 2 independent Michaelis-Menten functions.

\section{Pigment destruction and the estimation of ingestion rates by the gut fluorescence method}

In the gut fluorescence method, $I$ is equated with instantaneous defecation (gut evacuation) rate, thus:

$$
I=G \cdot k
$$

where $G$ is the gut pigment content (ng ind.$^{-1}$ ) and $k$ is the gut evacuation rate constant $\left(\mathrm{h}^{-1}\right)$. According to Head \& Harris (1996) all chl a destruction occurs prior to the entry of pigment into the copepod gut, so that the $I$ calculated by the expression above will not be the real ingestion rate $\left(I_{\mathrm{r}}\right)$, but an apparent ingestion rate $\left(I_{a}\right)$, which will be an underestimate. By definition:

$$
\left(G_{\mathrm{r}}-G_{\mathrm{d}}\right) / G_{\mathrm{r}}=D
$$

where $G_{r}$ is the gut pigment level which would be observed with no chl a destruction, $G_{\mathrm{d}}$ is the level that is actually measured, and $D$ is the degree of destruction (Note: $D$ is not expressed as a percentage, here). Thus, by simple algebra we can arrive at the expression:

$$
I_{\mathrm{a}} / I_{\mathrm{r}}=1-D
$$

In addition, however:

$$
D=\mathrm{CBE} / I_{\mathrm{r}}
$$

where CBE (chlorophyll bleaching enzyme activity) can be expressed using the 'double Michaelis-Menten' function given above. Thus, by substitution:

$$
\begin{array}{lrl} 
& I_{\mathrm{d}} / I_{\mathrm{r}}=1-\left(\mathrm{CBE} / I_{\mathrm{r}}\right) \\
\text { or } & I_{\mathrm{d}}=I_{\mathrm{r}}-(\mathrm{CBE}) \\
\text { or } & \\
I_{\mathrm{a}}= & \\
I_{\mathrm{r}}-\left\{\left[\left(V_{\mathrm{max}}^{\mathrm{c}} \cdot I_{\mathrm{r}}\right) /\left(K^{\mathrm{c}}+I_{\mathrm{r}}\right)\right]+\left[\left(R_{\max }^{\mathrm{p}} \cdot I_{\mathrm{r}}\right) /\left(K^{\mathrm{p}}+I_{\mathrm{r}}\right)\right] \cdot I_{\mathrm{r}}\right\}
\end{array}
$$

Gut fluorescence measurements give us $I_{a}$, but we need to determine $I_{\mathrm{r}}$. By rearrangement of Eq. (9), we can arrive the following expression for $I_{r}$ :

$$
\begin{aligned}
& \left(1-R^{\mathrm{p}}\right) \cdot I_{\mathrm{r}}^{3}+\left(K^{\mathrm{c}}+K^{\mathrm{p}}-V^{\mathrm{c}}-K^{\mathrm{c}} R^{\mathrm{p}}-I_{\mathrm{a}}\right) \cdot I_{\mathrm{r}}^{2} \\
& +\left[K^{\mathrm{c}} K^{\mathrm{p}}-V^{\mathrm{c}} K^{\mathrm{p}}-\left(K^{\mathrm{c}}+K^{\mathrm{p}}\right) I_{\mathrm{a}}\right] \cdot I_{\mathrm{r}}-K^{\mathrm{c}} K^{\mathrm{p}} I_{\mathrm{a}}=0 \\
& \text { where } V^{\mathrm{c}} \text { stands for } V_{\text {max }}^{\mathrm{c}} \text { and } R^{\mathrm{p}} \text { for } R_{\max }^{\mathrm{p}} \text {. }
\end{aligned}
$$

This cubic expression can have either 1 or 3 exact solutions (Press et al. 1986), but when the 3 sets of 
Table 5. Model parameters $V_{\max } R^{P}{ }_{\max } K^{\mathrm{c}}$ and $K^{\mathrm{P}}( \pm \mathrm{SE})$ given by the double Michaelis-Menten model for copepods that had fed during pre-bloom (Expts P1, P2 and P3) and early-bloom (Expts E1 and E2) conditions in situ and for data from Head \& Harris 11996), where copepods from late-bloom conditıons were fed natural assemblages of phytoplankton in vitro (Stns L1-L4)

\begin{tabular}{|c|c|c|c|c|}
\hline Feeding history of copepods & $V_{\max }$ & $R_{\max }^{p}$ & $K^{\mathrm{c}}$ & $K^{\mathrm{p}}$ \\
\hline Pre-bloom (P1, P2 and P3) & $2.78 \pm 3.85$ & $0.18 \pm 0.04$ & $1.52 \pm 7.25$ & $0.09 \pm 25.75$ \\
\hline Early-bloom (E1 and E2) & $6.14 \pm 12.04$ & $0.22 \pm 0.11$ & $3.70 \pm 17.97$ & $0.71 \pm 72.69$ \\
\hline Late-bloom (L1. L2, L3 and L4; Head \& Harris 1996) & $8.67 \pm 9.28$ & $0.55 \pm 0.56$ & $5.66 \pm 10.89$ & $36.93 \pm 120.50$ \\
\hline
\end{tabular}

experimentally derived values for $V_{\text {max }}^{c}, K^{c}, R_{\text {max }}^{p}$ and $K^{p}$ were inserted, there was in fact only 1 allowable solution in each of the 3 cases, for values of $I_{d}$ between zero and $100 \mathrm{ng}$ ind ${ }^{-1} \mathrm{~h}^{-1}$. The relationship between $I_{\mathrm{r}}$ and $I_{\mathrm{a}}$ in each case appears to be close to linear (Fig 10) and the relationship between the correction factor $\left(I_{\mathrm{r}} / I_{\mathrm{a}}\right)$, which must be applied to estimates of $I_{\mathrm{a}}$, looks (not surprisingly) something like the relationship between $\% D$ and $I$. Interestingly, when the correction factors are plotted versus $I_{\partial}$, using expanded $x$ or $y$ scales (Fig. 10), it becomes evident that at low values of $I_{\mathrm{a}}\left(<1 \mathrm{ng}\right.$ chl a ind $\left.\mathrm{-}^{-1} \mathrm{~h}^{-1}\right)$ the correction curves are almost identical for the early- and late-bloom cases (which had fairly similar $V_{\max }^{c}$ values), whereas at high values of $I_{\mathrm{a}}\left(>20 \mathrm{ng} \mathrm{chl} a\right.$ ind.$^{-1} \mathrm{~h}^{-1}$ ) values of $I_{\mathrm{r}} / I_{\mathrm{d}}$ are almost constant and nearly identical in the pre-and early-bloom cases (which had very similar $R_{\text {max }}$ values). This re-iterates what we have said above: at low ingestion rates, differences in copepod feeding history dominate, because the copepod enzyme is responsible for most of the chl a destruction, whereas at high ingestion rates, differences between phytoplankton foods are important, because the phytoplankton enzyme is responsible for most of the chl a destruction.

One of our original objectives was to see if an increased understanding of the factors affecting the degree of chl a destruction during grazing would help us to 'correct' estimates of apparent copepod ingestion rates $\left(I_{d}\right.$ values) determined using the gut fluorescence method. We think that our new model and the correction factors that we have derived from it will enable us to do so, at least for Calanus spp. grazing on diatoms during a spring-bloom. Moreover, we think it should be sufficient to use one set of average values for the parameters $V_{\max }^{\mathrm{c}}, K^{\mathrm{c}}, R_{\max }^{\mathrm{p}}$ and $K^{\mathrm{p}}$ for Calanus spp. grazing at all stages of a spring-bloom, since at a given value of $I_{a}$, the correction factors for our different data sets varied only by a factor of between 2.0 for $I_{\mathrm{a}}=$ $0.1 \mathrm{ng}$ chl $a$ ind.$^{-1} \mathrm{~h}^{-1}$ and $<1.6$ for values of $I_{\mathrm{a}} \geq 20 \mathrm{ng}$ chl $a$ ind..$^{-1} h^{-1}$. By contrast, however, the variation in correction factors with $I_{a}$ must be taken into account, since these ranged (in our data) between an average of $>8.3$ for values of $I_{\mathrm{a}} \leq 0.5 \mathrm{ng} \mathrm{chl} a$ ind.$^{-1} \mathrm{~h}^{-1}$ and of $<1.6$ for values of $I_{\mathrm{d}} \geq 20 \mathrm{ng}$ chl $a$ ind.$^{-1} \mathrm{~h}^{-1}$. When it comes to assessing the possibility of a more general applica-
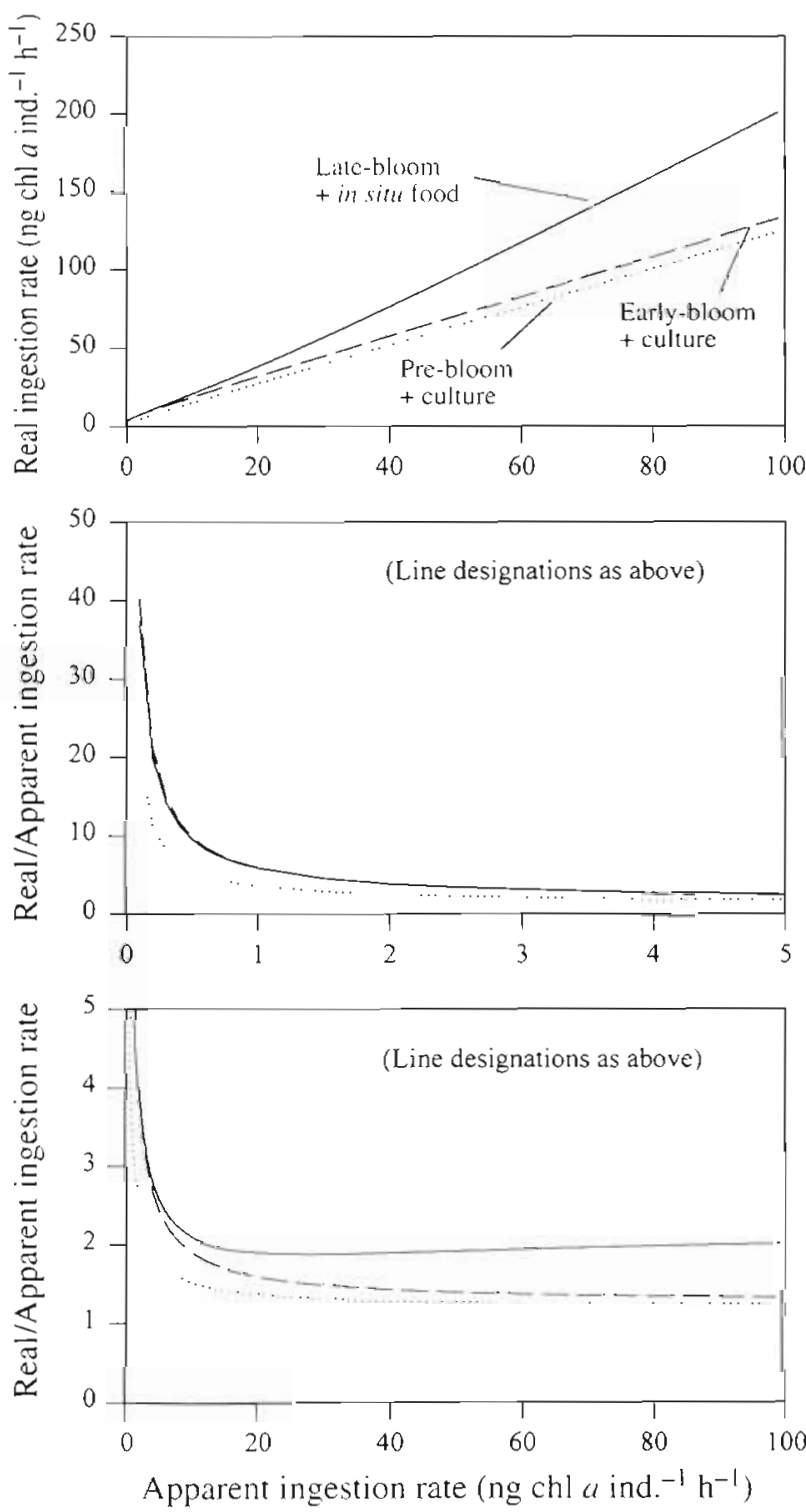

Fig. 10. Relationship between real ingestion rate $\left(I_{r}\right)$ and apparent ingestion rate $\left(I_{\mathrm{d}}\right)$ as would have been determined by gut fluorescence measurements, for pre-, early- and latebloom copepods, predicted from the 'double MichaelisMenten model' description of chl a destruction during grazing (upper panel). Relationship between the 'correction factor' $\left(I_{r} / I_{n}\right)$, which must be applied to apparent ingestion rates determined using gut fluorescence $\left(I_{a}\right)$, and apparent ingestion rate, over selected ranges of $f_{\mathrm{a}}$ (2 lower panels) 
tion of our model, our knowledge is as yet too limited to comment. We need to collect data for other types of copepods feeding on other types of phytoplankton over a range of ingestion rates, to see whether variations in the kinetic parameters ( $V_{\max }, R_{\max }$ and $K$ values) significantly alter the shape of the curve relating the correction factor $\left(I_{r} / I_{\mathrm{a}}\right)$ to apparent ingestion rate $\left(I_{\mathrm{a}}\right)$ in different environmental situations. It seems obvious that the areas in which chl a destruction during grazing will have the most important effect will be areas with low in situ chl a concentrations and therefore low copepod ingestion rates (e.g. oligotrophic regions). These are areas that need attention. Overall, however, we are optimistic that the information base necessary to generalise our approach is attainable and we are hopeful that our model parameters may prove relatively robust. If so, and if it is known that in a given environmental situation a-type phaeopigments are the main chl a degradation products (e.g. Head \& Harris 1994), then we suggest that use of a modified gut fluorescence method for the estimation of in situ herbivorous ingestion rates should continue, since the advantages of this method probably outweigh the disadvantages of alternative in vitro methods (e.g. Roman \& Rublee 1980, Osborn 1996).

Acknowledgements. We thank. Leslie Harris for collecting the copepods and helping with their identification; Jeff Anning, Jeff Spry, Brian Irwin and Alastair Macdonald for providing the nutrient and particulate chlorophyll data; the officers and crew of the C.S.S. 'Hudson' for their help in the field; Heidi Maass for advice on the mathematical formulations; and Trevor Platt and Bill Li for comments on a earlier version of the manuscript.

\section{LITERATURE CITED}

Bochdansky AB, Deibel D (1997) Destruction of chloropigments in copepod guts. Mar Ecol Prog Ser 147:301-303

Brown SB, Houghton JD, Hendry GAF (1991) Chlorophyll breakdown. In: Scheer $H$ (ed) Chlorophylls. CRC Press, London, p 465-489

Conover RJ, Durvasula R, Roy S, Wang R (1986) Probable loss of chlorophyl-derived pigments during passage through the gut of zooplankton, and some of the consequences. Limnol Ocearogr 31:432-435

Frost BW (1972) Effects of the size and concentration of food particles on the feeding behavior of the marine planktonic copepod, Calanus pacificus. Limnol Oceanogr 17:805-825 Head EJH (1997), Reply to the comment of Bochdansky and

Editorial responsibulity: Otto Kinne (Editor),

Oldendorf/Luhe, Germany
Deibel. Mar Ecol Prog Ser 147:305-306

Head EJH, Harris LR (1992) Chlorophyll and carotenoid transformation and des:ruction by Calanus spp. grazing on diatoms. Mar Ecol Prog Ser 86:229-238

Head EJH, Harris LR (1994) Feeding selectivity by copepods grazing on natural mixtures of phytoplankton determined by HPLC analysis of pigments. Mar Ecol Prog Ser 110: $75-83$

Head EJH, Harris LR (1996) Chlorophyll destruction by Calanus spp. grazıng on phytoplankton: kinetics, effects of ingestion rate and feeding history, and a mechanistic interpretation. Mar Ecol Prog Ser 135:223-235

Head EJH, Horne EPW (1993) Pigment transformation and vertical flux in an area of convergence in the north Atlantic. Deep-Sea Res 40:329-346

Jeffrey SW, Mantoura RFC, Wright SW (1997) Phytoplankton pigments in oceanography. Monographs on oceanographic methodology 10, UNESCO. Paris

Lopez MDG, Huntley ME, Sykes PF (1988) Pigment destruction by Calanus pacificus: impact on the estimation of water column fluxes. J Plankton Res 4:715-734

Mackas DL, Hohrer R (1976) Fluorescence analysis of zooplankton gut contents and an investigation of diel feeding patterns. J Exp Mar Biol Ecol 25:77-85

Osborn, $T$ (1996) The role of turbulent diffusion for copepods with feeding currents. J Plankton Res 18:185-195

Owens TG, Falkowski PG (1982) Enzymatic degradation of chlorophyll a by marine phytoplankton in vitro. Phytochemistry 21:979-984

Pasternak AF, Drits AV (1988) Possible degradation of chlorophyll-derived pigments during gut passage of herbivorous copepods Mar Ecol Prog Ser 21:979-984

Penry DL, Frost BW (1991) Chlorophyll-a degradation by Calanus pacificus: dependence on ingestion rate and digestive acclimation to food resources. Limnol Oceanogr 36:147-159

Peterson W, Painting S, Barlow R (1990) Feeding rates of Calanoides carinatus: a comparison of five methods including evaluation of the gut fluorescence method. Mar Ecol Prog Ser 63:85-92

Press WH, Flannery BP, Teukolsky SA, Vetterling WT (1986) Numerical recipes: the art of scientific computing, Chap 5, Evaluation of functions. Cambridge University Press, Cambridge, p 131-154

Roman MR, Rublee PA (1980) Containment effects in copepod grazing experiments: a plea to end the black box approach. Limnol Oceanogr 25:982-990

Runge, JA (1980) Effects of hunger and season on the feeding behavior of Calanus pacificus. Limnol Oceanogr 25: $134-145$

Spooner N, Harvey HR, Pea.ce GES, Eckardt CB, Maxwell JR (1994) Biological defunctionalisation of chlorophyll in the aquatic environment. II. Action of endogenous algal enzymes and aerobic bacteria. Org Geochem 22:773-780

Yentsch CS, Menzel DW (1963) A method of the determination of phytoplankton chlorophyll and phaeophytin by fluorescence. Deep-Sea Res 10:221-231

Submitted: February 11, 1998; Accepted: July 1, 1998

Proofs received from author(s): Scptember 4, 1998 